Pediat. Res. 2: 149-160 (1968)

$\begin{array}{ll}\text { Cystathionase } & \text { homoserine } \\ \text { cystathionine } & \text { pyridoxine } \\ \text { cystine } & \text { serine } \\ \text { homocystinuria } & \end{array}$

\title{
The Biosynthesis of Cystathionine in Patients with Homocystinuria
}

\author{
P.W.K.Wong ${ }^{[30]}$, V.SGHWARz and G.M.KOMROWER \\ Department of Medical Biochemistry, University of Manchester, \\ and the Mental Retardation Unit, Royal Manchester Children's Hospital, Manchester, England
}

\section{Extract}

The synthesis in rat and normal human liver homogenates of cystathionine from homoserine + cysteine was studied. When cystathionine was used as substrate, cyst(e)ine was formed and incubation of liver homogenate with homoserine + cysteine resulted in the formation of cystathionine.

Incubation of homogenate prepared from homocystinuric liver with L-homoserine +DL-cysteine${ }^{3-14} \mathrm{C}$ or DL-cysteine- ${ }^{35} \mathrm{~S}$ resulted in the formation of labelled cystathionine. The identity of cystathionine was established in three chromatographic separations.

Oral loading with homoserine and cysteine or cystine in two patients with homocystinuria resulted in urinary excretion of cystathionine in amounts similar to that reported in normal human subjects without amino acid loading.

\section{Speculation}

The observation that human and monkey brains contain much larger quantities of cystathionine than those of other species [26] suggests a special relation of this amino acid to the normal development and function of the primate brain. Cystathionine is either absent from or markedly deficient in the brain of untreated homocystinuric patients [2, 9]. Since we have shown that synthesis of cystathionine from homoserine and cysteine does take place in the patient's liver in vitro, supplementation of the diet with homoserine and cysteine may prove effective in raising intracellular cystathionine concentration toward the normal, and may possibly improve the prognosis in this disease.

\section{Introduction}

Homocystinuria was discovered by Field et al. [4] in Northern Ireland and by GERRITSEN et al. [8] in the United States of America. The disorder is characterized by mental retardation, iridodonesis, ectopia lentis, seizures, thrombo-embolic tendency, skeletal abnormalities such as osteoporosis, dolichostenomelia and arachnodactyly $[3,23]$. Intimal ridges were found in large and medium arteries resulting from fibrous thickening and fragmentation of elastic tissue in the vessel walls.
Fatty infiltration was observed in the liver in all cases examined [10]. MudD et al. [16] demonstrated that there was a deficiency of cystathionine synthetase (4.2.1.13) activity in the liver of a typical case who was mentally retarded (fig. 1). A paternal cousin of this patient, who was mentally normal but had homocystinuria, had cystathionine synthetase activity approximately $10 \%$ of that normally found in the liver [5]. It was also demonstrated that the brain of a homocystinuric patient was deficient in cystathionine synthetase, but had normal activities of cystathionase and methionine 


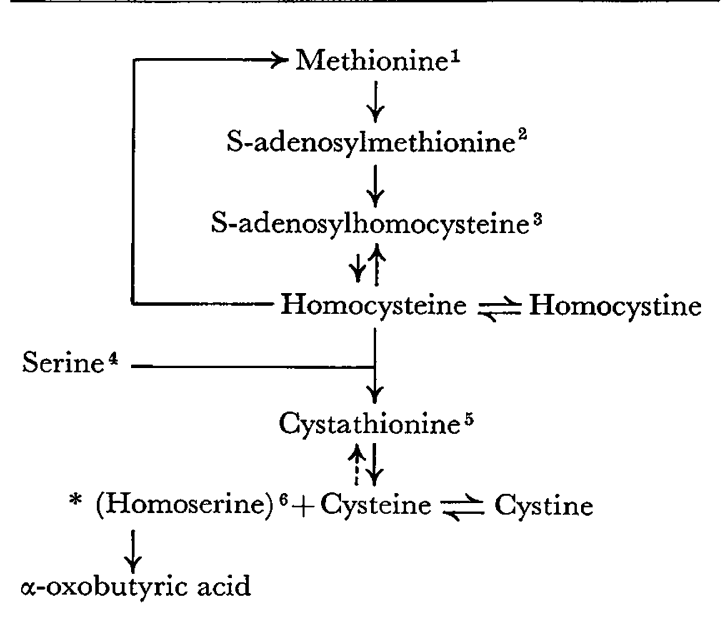

Metabolic pathways of methionine

1 ATP: L-methionine S-adenosyltransferase (2.5.1.6).

2 S-adenosylmethionine: L-homocysteine S-methyltransferase (2.1.1.10)

${ }^{3}$ S-adenosyl: L-homocysteine hydrolase (3.3.1.1).

4 Cystathionine synthetase (L-serine hydrolyase) (4.2.1.13).

${ }^{5}$ Cystathionase (L-homoserine hydrolyase) (4.2.1.15).

${ }^{6}$ Homoserine deaminase (L-homoserine hydrolyase) (4.2.1.15).

* Free homoserine is not normally a product of cystathionase.

Numbers following enzymes refer to Enzyme Commission classification [29].

Fig. 1. Metabolic pathways of methionine.

activating enzyme [14]. The metabolic block in this disorder resulted in the accumulation of methionine and homocystine and a deficiency of cystathionine and endogenous cystine [2, 3, 9].

The pathogenesis of mental deficiency in this disease had not been defined. TALLAN et al. [26] found much higher concentrations of cystathionine in the human and monkey brains than in the brains of other animals; Shimizu et al. [24] demonstrated that these high concentrations were not due to postmortem artifacts. These findings have given rise to the suggestion that cystathionine may be essential for the normal development and function of the human brain. Supplementation of cystathionine in the dietary treatment of homocystinurics, however, has never been attempted because of the cost and high renal clearance of the amino acid [6]. The present study was undertaken to establish whether cystathionine could be synthesized from homoserine and cysteine in patients with homocystinuria.

\section{Case Reports}

Case 1 was a nine-year-old girl with the classical signs and symptoms of homocystinuria, fair complexion, malar flush, severe mental retardation, poor peripheral circulation, an enlarged and palpable liver, and bilateral dislocation of the lenses. She had prominent knock knee and had suffered many 'salaam' attacks and generalized convulsions. Her electroencephalogram (EEG) showed epileptic activity. Generalized osteoporosis was observed in x-rays of her bones. Her urine was positive for the cyanide-nitroprusside reaction; two-dimensional paper chromatography of urine, after oxidation, showed a strong spot of homocysteic acid. She had been given a low methionine diet with cystine supplement for three years. Her daily intake of methionine was $480 \mathrm{mg}(20 \mathrm{mg} / \mathrm{kg}$ of body weight) and her cystine supplement was $1 \mathrm{~g} /$ day. On the first day of the experiments, her levels in plasma, $\mathrm{mg} / 100 \mathrm{ml}$ of pertinent amino acids, were: methionine, 0.6 ; homocystine, 0.2 ; and cystine, 0.5 .

Case 2, a $41 \frac{1}{2}$-year-old girl, was physically and mentally retarded (IQ 73, 83 and 82 at 3 years 5 months, 4 years, and 4 years 7 months respectively). Several episodes had been noted in which the child appeared to be unable to see, had upward deviation of the eyes, and was very vague. In addition, there had been one left-sided convulsion. The EEG record showed a generalized excess of slow wave activity with no focal features or epileptic discharges. Physical examination showed that she had coarse hair, malar flush, clumsy gait with her left foot twisted outwards, stiff joints, and nystagmus. Eye examination showed that she had compound myopia, astigmatism, and iridodonesis. The most recent examination showed an upward dislocation of the right lens and some nasal dislocation of the left lens. Her urine gave a positive cyanide-nitroprusside reaction. Two-dimensional paper chromatography of oxidized urine showed a strong spot of homocysteic acid. She had been treated with a low methionine diet $(20 \mathrm{mg} / \mathrm{kg}$ of body weight) and cystine supplement ( $1 \mathrm{~g}$ daily) for 1 year and 4 months. At the time of the experiments, her plasma methionine level was $0.8 \mathrm{mg} /$ $100 \mathrm{ml}$; homocystine was not detected. (Homocystine had been detected on many previous occasions.)

\section{Materials and Methods}

Chemicals

Radioactive cystine (DL-cysteine-3-14 $\mathrm{G}$ and DL-cysteine- ${ }^{35} \mathrm{~S}$ ) was obtained from the Radiochemical Center, Amersham. The manufacturers stated that purity by dilution analysis as S-carbamido-methyl-DL-cysteine was $99 \%$ and chemical purity by colorimetric estimation with 5,5-dithiobis (2-nitrobenzoic acid) was 
$101 \%$. Purity by paper chromatography was not established, since partial oxidation to cystine occurred even when the cysteine was chromatographed in an atmosphere of 'oxygen-free' nitrogen. Ion exchange chromatograms of the ${ }^{14} \mathrm{C}$ and ${ }^{35} \mathrm{~S}$-cysteine showed neither radioactivity nor ninhydrin positive substance at the region of the chromatograms where cystathionine was expected. A radioactive contaminant of 0.1 to $0.2 \%$ could have been detected by this method.

Cystathionine was obtained from the British Drug House.

\section{Ion Exchange Chromatography}

Column chromatography of amino acids was carried out by a modification of the method of PIEz and MoRRIS [21], using a Technicon Amino Acid Autoanalyzer with a column $0.55 \mathrm{~cm}$ in diameter and $130 \mathrm{~cm}$ in length, packed with type 'A' chromo-beads. Total running time was 21 hours. Methanol was not used in the first and second chambers of the 'autograd', since this was found to result in overlapping of the cystine and methionine peaks, and of the cystathionine and isoleucine peaks. The $\mathrm{pH}$ gradient as recommended in the company's manual for a $0.55 \mathrm{~cm}$ column was used because it gave good resolution of cystathionine from cystine, methionine, and isoleucine. Thiodiglycol was used as the antioxidant; norleucine was used as the internal standard. The identity of the individual amino acid was verified by adding authentic marker to the samples. Duplicate runs gave reproducibility within $10 \%$ in quantities above $0.01 \mu$ mole.

Using a short column $(65 \mathrm{~cm})$ and the buffer gradient recommended by the Technicon manual for protein hydrolysate (12 $1 / 2$-hour run), PERRY et al. [20] found that the mixed disulfide of cysteine and homocysteine emerged from the resin column at the same point as norleucine, the internal standard. In the present studies, a long column $(130 \mathrm{~cm})$ and the buffer system for a 21-hour run were employed. This system permitted satisfactory separation of norleucine from the mixed disulfide which was eluted from the column after norleucine.

\section{Collection of Fractions}

A 'split stream technique' was used to collect fractions of the effluent. This permitted definition of the individual fractions in terms of the ninhydrin peaks as recorded on the flow sheet.

\section{Determination of Plasma and Urinary Amino Acids}

To minimize adsorption of amino acids on plasma proteins, heparinized venous blood was immediately centrifuged and the plasma proteins were precipitated with 5 volumes of $0.9 \%$ picric acid. The excess picric acid was removed by ion exchanger (Dowex 2, chloride form, 200-400 mesh). The samples were frozen at $-20^{\circ}$ until required for analysis. A volume equivalent to $0.5,1.0$ or $1.5 \mathrm{ml}$ of plasma was used for column chromatography.

Urine was collected after the method of BALDWIN et al. [1]. Thymol was used as the preservative and all samples were frozen at $-20^{\circ}$ until analysis. An aliquot of $0.2,0.4$ or $0.6 \mathrm{ml}$ was used for column chromatography.

\section{Preparation of Liver Homogenate}

In preliminary experiments, liver was obtained from adult white rats. The rats were killed by a blow on the head. The liver was immediately removed and washed with cold $0.9 \%$ saline. A piece of liver approximately $1 \mathrm{~g}$ in weight was cut with scissors into small fragments. About 2 to 5 volumes of cold 0.2 molar phosphate buffer, pH $7.5\left(0.2 \mathrm{~m}-\mathrm{KH}_{2} \mathrm{PO}_{4}\right.$ adjusted with $\left.\mathrm{NaOH}\right)$ were added and the mixture was homogenized in a glass homogenizer, cooled in ice. The homogenate was centrifuged in a refrigerated centrifuge at $2-4^{\circ}$ and at $2,000 \times \mathrm{G}$ for 20 minutes. The metabolism of cystathionine was studied in this supernatant.

Specimens of normal human liver were obtained from biopsies of adult patients who had gastrectomy or cholecystectomy because of gallstones. In these patients, liver function tests were normal and, at operation, the livers were of normal appearance. Approximately $1 \mathrm{~g}$ of tissue was obtained at each biopsy and was processed as described for the rat liver.

Liver was obtained from an open biopsy from Case 1. The liver sample was processed in the manner described for rat and control human tissue except that the homogenate was not centrifuged, since no refrigerated centrifuge was available. Instead, the homogenate was kept in ice for 30 minutes to allow the large particles to settle to the bottom of the tube before the supernatant was removed for use in the experiments.

\section{Incubation Mixture}

A modification of the procedure of Matsuo and GReEnBerg [15] was used. Optimum incubation conditions for human or rat liver homogenates were not investigated. However, addition of sodium cyanide or exclusion of oxygen by incubating in an atmosphere of nitrogen did not improve the yield of cystathionine. The incubation mixture contained $0.2 \mathrm{ml}$ of buffered liver supernatant (as described previously) and one or more of the following substrates : cysteine, homoserine, homocysteine, serine and cystathionine (see tables I through VI). The final volume was $0.22 \mathrm{ml}$. Incubation was carried out in air at $37^{\circ}$ with constant shaking for 30 minutes or one hour. The reaction was terminated by the addition of $0.8 \mathrm{ml}$ of $0.9 \%$ picric acid. After 10 minutes, sufficient Dowex 2 (chloride form) was added 
to produce a colorless solution and the mixture was centrifuged. The clear supernatant was transferred to the column and the precipitate was washed four times with $2 \mathrm{ml}$ of buffer $\mathrm{pH} 2.79$ as used in the 'autograd'. Each of the washings was transferred to the column.

\section{Determination of Radioactivity}

A modification of the method of GrLL [11] was employed for the determination of radioactivity in the fractions. An $0.5 \mathrm{ml}$ aliquot of each fraction was applied without desalting to a piece of rectangular glass fiber paper (Whatman GF $810.25 \mathrm{~mm}$ thick) measuring $75 \times 18 \mathrm{~mm}$. The paper was dried under reduced pressure at $60^{\circ}$ and rolled into a cylinder for insertion into a counting vial containing $10 \mathrm{ml}$ of toluene with $0.5 \%$ 2,5-diphenyloxazole. An automatic liquid scintillation counter (Nuclear Chicago 702 series) was used for counting. The efficiency of this method was $70 \%$. Duplicate counts agreed within 2 to $3 \%$. No correction for radioactive decay was made but the 'control samples' of the experiments were always counted before the "test samples'. The specific activity of the labelled cysteine was determined by diluting a known amount with the buffer as used in the 'autograd' and counting it on glass paper as described.

\section{Calculation of Specific Activity}

The specific activity of the labelled amino acids was determined by: (a) calculation of the quantity of amino acid by the ninhydrin reaction as recorded on the flow sheet of the amino acid analyser; (b) determination of the total radioactivity (counts per minute) corresponding to the ninhydrin peak; and (c) calculation of the specific activity as the total counts per minute per $\mu$ mole of amino acid, without correction for the efficiency of the method of counting.

Localization of Radioactivity on Paper Chromatograms

Radioactive paper chromatograms were scanned in a Nuclear Chicago Actigraph III.

\section{Protein Determination}

Protein determination on the liver supernatant was carried out by a modification of the biuret method [18].

\section{Results}

\section{Experiments with Rat Liver}

Table I summarizes the experimental conditions and results of incubations using nonradioactive substrates and supernatant of homogenate of rat liver. It can be seen that the supernatant contained only a small amount of cystine (cysteine) and no detectable cystathionine (tube 1-1). Very little cystathionine was form- ed when L-cysteine or DL-homoserine was added to the incubation mixture (tubes 1-2 and 1-3). On the other hand, a substantial quantity of cystathionine was found in the incubate containing both L-cysteine and DLhomoserine (tube 1-4). More than twice as much cystathionine was formed from DL-homocysteine+DLserine (tube 1-6) and much less without added serine (tube 1-5). The formation of cystine (cysteine) from cystathionine was demonstrated in tube 1-7. These observations confirmed the formation of cystathionine from homoserine + cysteine in the rat liver first reported by Matsuo and Greenberg [15].

\section{Experiments with Adult Human Liver}

Table II summarizes the experimental conditions and the results of incubations using the supernatant of 'normal' human liver homogenate of a biopsy from a 36 -year-old female. It can be seen that the synthetic and degradative reactions catalyzed by human liver homogenate are qualitatively similar to those observed in rat liver preparations. Cystathionine was synthesized from homocysteine + serine (tube 2-5), but little or nothing was obtained in the absence of exogenous serine (tube 2-4). The synthesis of a small amount of cystathionine from cysteine thomoserine is suggested by the cystathionine found in tube 2-2. Addition of pyridoxal-5-phosphate and ATP did not improve the net synthesis of cystathionine (tube 2-3).

\section{Experiments with Infant Liver Obtained Post Mortem}

Table III summarizes the experimental conditions and results of incubations using the supernatant of a liver homogenate from a one-year-old infant obtained post mortem. It can be seen that whereas the blank tube (tube 3-1) contained only a trace of cystathionine, the test aliquot (tube 3-2) contained an amount of cystathionine suggestive of synthesis from the added substrates. Because of the small quantities of cystathionine synthesized by human liver homogenates, it was decided to use labelled cysteine in future experiments.

\section{Experiments with Radioactive Cysteine}

Table IV shows the results obtained with rat liver supernatant and DL-cysteine- $3-{ }^{14} \mathrm{C}$ as one of the substrates. The specific activity of the cysteine was $5.8 \times 10^{6}$ counts $/ \mathrm{min} / \mu$ mole. Only a trace of labelled cystathionine was formed on incubation with cysteine (tube 4-2). In the presence of homoserine and cysteine (tube 4-3), however, a considerable amount of cystathionine was obtained. The specific activity of $6.3 \times 10^{6}$ counts/ $\mathrm{min} / \mu$ mole was virtually the same as that of the original substrate.

Table V summarizes the results obtained with 'normal' human liver obtained from two control subjects and labelled cysteine (DL-cysteine- ${ }^{35} \mathrm{~S}$ or DL-cysteine-3- 
The biosynthesis of cystathionine in patients with homocystinuria

Table I. Rat liver homogenate

\begin{tabular}{|c|c|c|c|c|c|c|c|}
\hline \multirow{2}{*}{$\begin{array}{l}\text { Tube } \\
\text { No. }\end{array}$} & \multicolumn{5}{|c|}{ Substrates ( $\mu$ mole) } & \multicolumn{2}{|c|}{ Products ( $\mu$ mole $)$} \\
\hline & $\begin{array}{l}\text { DL- } \\
\text { homoserine }\end{array}$ & $\begin{array}{l}\text { L-cysteine } \\
\text { hydro- } \\
\text { chloride }\end{array}$ & $\begin{array}{l}\text { oL-cysta- } \\
\text { thionine }\end{array}$ & $\begin{array}{l}\text { DL-homo- } \\
\text { cysteine }\end{array}$ & DL-serine & $\begin{array}{l}\text { Cysta- } \\
\text { thionine }\end{array}$ & Cystine \\
\hline $1-1$ & - & - & - & - & - & N.D. ${ }^{1}$ & trace \\
\hline $1-2$ & - & 4.0 & - & - & - & 0.008 & -2 \\
\hline $1-3$ & 4.0 & - & - & - & - & trace & trace \\
\hline $1-4$ & 4.0 & 4.0 & - & - & - & 0.167 & -3 \\
\hline $1-5$ & - & - & - & 4.0 & - & 0.029 & -2 \\
\hline $1-6$ & - & - & - & 4.0 & 4.0 & 0.372 & -2 \\
\hline $1-7$ & - & - & 4.0 & - & - & -3 & 0.022 \\
\hline
\end{tabular}

All tubes contained supernatant of rat liver homogenate as enzyme source ( $2.56 \mathrm{mg}$ liver protein) and were incubated for $30 \mathrm{~min}$.

1 Not detectable.

2 The cystine peak was obscured by the large methionine peak.

${ }^{3}$ Concentration too high for accurate measurement by Technicon recorder.

Table II. Normal human liver homogenate

\begin{tabular}{|c|c|c|c|c|c|c|c|}
\hline \multirow{2}{*}{$\begin{array}{l}\text { Tube } \\
\text { No. }\end{array}$} & \multicolumn{5}{|c|}{ Substrates $(\mu$ mole $)$} & \multicolumn{2}{|c|}{ Products ( $\mu$ mole $)$} \\
\hline & $\begin{array}{l}\text { DL- } \\
\text { homoserine }\end{array}$ & $\begin{array}{l}\text { L-cysteine } \\
\text { hydro- } \\
\text { chloride }\end{array}$ & $\begin{array}{l}\text { oL-cysta- } \\
\text { thionine }\end{array}$ & $\begin{array}{l}\text { DL-homo- } \\
\text { cysteine }\end{array}$ & DL-serine & $\begin{array}{l}\text { Cysta- } \\
\text { thionine }\end{array}$ & Cystine \\
\hline $2-1$ & - & - & - & - & - & 0.003 & 0.006 \\
\hline $2-2$ & 4.0 & 4.0 & - & - & - & 0.009 & -2 \\
\hline $2-3^{1}$ & 4.0 & 4.0 & - & - & - & 0.006 & -2 \\
\hline $2-4$ & - & - & - & 4.0 & - & 0.004 & -3 \\
\hline $2-5$ & - & - & - & 4.0 & 4.0 & 0.063 & -3 \\
\hline $2-6$ & - & - & 4.0 & - & - & -2 & 0.019 \\
\hline
\end{tabular}

All tubes contained supernatant of 'normal' liver homogenate (2.36 mg liver protein) from a 36-year-old female (subject A) and were incubated for $60 \mathrm{~min}$.

1 The incubation mixture also contained $50 \mu$ mole of pyridoxal-5-phosphate and $40 \mu$ mole of ATP.

2 Concentration too high for accurate measurement.

${ }^{3}$ The cystine peak was obscured by the large methionine peak.

Table III. Homogenate of infant liver obtained post mortem

\begin{tabular}{lllllll}
\hline Tube No. & \multicolumn{2}{c}{ Substrates $(\mu \mathrm{mole})$} & & \multicolumn{2}{c}{ Products $(\mu$ mole $)$} \\
\cline { 2 - 3 } & DL-homoserine & $\begin{array}{l}\text { L-cysteine } \\
\text { hydrochloride }\end{array}$ & $\begin{array}{l}\text { DL-cysta- } \\
\text { thionine }\end{array}$ & & Cysta- & Cystine \\
$3-1$ & - & - & & & thionine & \\
$3-2$ & 4.0 & 4.0 & - & & 0.003 & 0.019 \\
$3-3$ & - & - & 4.0 & & 0.014 & -1 \\
\hline
\end{tabular}

All tubes contained supernatant of post-mortem human liver homogenate ( $5.45 \mathrm{mg}$ liver protein) from an infant who died of meningitis. Autopsy was performed 4 hours after death and the liver was frozen at $-40^{\circ}$ for 36 hours before study. All incubations were for 30 minutes.

${ }^{1}$ Concentration too high for accurate measurement. 
Table IV. Rat liver homogenate

\begin{tabular}{|c|c|c|c|c|c|}
\hline \multirow[t]{2}{*}{ Tube No. } & & \multicolumn{2}{|c|}{ Substrates $(\mu$ mole $)$} & \multicolumn{2}{|c|}{ Gystathionine } \\
\hline & & L-homoserine & $\begin{array}{l}\text { DL-cysteine- } 3-14 \mathrm{C} \\
\text { hydrochloride }\end{array}$ & $\mu$ mole & $\begin{array}{l}\text { specific activity } \\
\mathrm{cts} / \mathrm{min} / \mu \text { mole }\end{array}$ \\
\hline $4-1$ & blank & - & - & N.D. ${ }^{1}$ & - \\
\hline $4-2$ & control & - & 1.98 & trace & $-^{2}$ \\
\hline $4-3$ & test & 2.0 & 1.98 & 0.033 & $6.3 \times 10^{6}$ \\
\hline
\end{tabular}

All tubes contained supernatant of rat liver homogenate (1.45 $\mathrm{mg}$ liver protein) and were incubated for $60 \mathrm{~min}$. 1 Not detectable.

2 Total counts: $1.1 \times 10^{4} \mathrm{cts} / \mathrm{min}$.

Table V. Normal human liver homogenate

\begin{tabular}{|c|c|c|c|c|c|c|}
\hline \multicolumn{2}{|c|}{ Tube No. } & \multicolumn{3}{|c|}{ Substrates ( $\mu$ mole) } & \multicolumn{2}{|c|}{ Cystathionine } \\
\hline & & \multirow{2}{*}{$\begin{array}{l}\text { L-homo- } \\
\text { serine }\end{array}$} & \multirow{2}{*}{$\begin{array}{l}\text { DL-cysteine- } \\
3{ }^{14} \mathrm{C} \text { hydro- } \\
\text { chloride } \\
-\end{array}$} & \multirow{2}{*}{$\begin{array}{l}\begin{array}{l}\text { DL-cysteine- }{ }^{35} \mathrm{~S} \\
\text { hydro- } \\
\text { chloride }\end{array} \\
-\end{array}$} & \multirow{2}{*}{ $\mu$ mole } & \multirow{2}{*}{$\begin{array}{l}\text { specific } \\
\text { activity } \\
\mathrm{cts} / \mathrm{min} / \mu \mathrm{mole}\end{array}$} \\
\hline $5-1$ & blank & & & & & \\
\hline $5-2$ & control & - & - & 2.44 & 0.012 & $23.1 \times 10^{6}$ \\
\hline $5-3$ & test & 2.0 & - & 2.44 & 0.014 & $44.1 \times 10^{6}$ \\
\hline $5-4$ & blank & - & - & - & trace & - \\
\hline $5-5$ & control & - & 1.98 & - & 0.002 & -1 \\
\hline $5-6$ & test & 2.0 & 1.98 & - & 0.034 & $1.9 \times 10^{6}$ \\
\hline
\end{tabular}

Tubes 5-1 to 5-3 contained supernatant of 'normal' human liver homogenate (12.08 mg liver protein) from a 24-year-old female (Subject B). Tubes 5-4 to 5-6 contained supernatant of 'normal' human liver homogenate (18.38 mg liver protein) from a 47-year-old male (Subject G). All incubations were for $60 \mathrm{~min}$.

1 Total counts: $2 \times 10^{3} \mathrm{cts} / \mathrm{min}$.

Table VI. Homocystinuric liver homogenate

\begin{tabular}{|c|c|c|c|c|c|c|}
\hline \multicolumn{2}{|c|}{ Tube No. } & \multicolumn{3}{|c|}{ Substrates ( $\mu$ mole) } & \multicolumn{2}{|c|}{ Cystathionine } \\
\hline & & \multirow{2}{*}{$\begin{array}{l}\text { L-homo- } \\
\text { serine } \\
-\end{array}$} & \multirow{2}{*}{$\begin{array}{l}\text { DL-cysteine- } \\
3-^{14} \mathrm{C} \text { hydro- } \\
\text { chloride } \\
\text { - }\end{array}$} & \multirow{2}{*}{$\begin{array}{l}\text { DL-cysteine- }{ }^{35} \mathrm{~S} \\
\text { hydro- } \\
\text { chloride }\end{array}$} & \multirow{2}{*}{$\begin{array}{l}\mu \text { mole } \\
\text { N.D. }{ }^{1}\end{array}$} & \multirow{2}{*}{$\begin{array}{l}\text { specific } \\
\text { activity } \\
\text { cts/min } / \mu \text { mole }\end{array}$} \\
\hline $6-1$ & blank & & & & & \\
\hline $6-2$ & control & - & - & 2.44 & N.D. & -2 \\
\hline $6-3$ & test & 2.0 & - & 2.44 & 0.042 & $13.6 \times 10^{6}$ \\
\hline $6-4$ & control & - & 2.47 & - & N.D. & -3 \\
\hline $6-5$ & test & 2.0 & 2.47 & - & 0.022 & $5.7 \times 10^{6}$ \\
\hline
\end{tabular}

All tubes contained supernatant of liver homogenate $(11.78 \mathrm{mg}$ liver protein) from a homocystinuric patient (case 1) and were incubated for $60 \mathrm{~min}$.

1 Not detectable.

${ }^{2}$ Total counts: $3 \times 10^{4} \mathrm{cts} / \mathrm{min}$.

3 Total counts : $1 \times 10^{3} \mathrm{cts} / \mathrm{min}$. 
${ }^{14} \mathrm{C}$, with specific activities of $41.0 \times 10^{6}$ counts $/ \mathrm{min} /$ $\mu$ mole and $5.8 \times 10^{6}$ counts $/ \mathrm{min} / \mu$ mole respectively). A small amount of cystathionine was found in the incubates containing either cysteine-- ${ }^{35} \mathrm{~S}$ alone (tube 5-2) or cysteine- ${ }^{35} \mathrm{~S}+$ homoserine (tube 5-3). Cystathionine in both experiments was labelled, but the specific activity was higher in the latter from tube 5-3. Supernatant obtained from Subject Cyielded little cystathionine, labelled or unlabelled, on incubation with DLcysteine- ${ }^{14} \mathrm{C}$ (tube $5-5$ ), and considerably more of both when homoserine was also present (tube 5-6).

In the case of the homocystinuric patient (Case 1), the liver homogenate was not contrifuged. Instead, the homogenate was kept in ice for 30 minutes before aliquots were pipetted into tubes $6-1$ to $6-5$ (table VI). For this reason, we believe that the supernatant was somewhat less homogeneous than that obtained from human control and rat livers. Incubations were carried out with or without added homoserine and cysteine. The specific activity of the DL-cysteine ${ }^{35} \mathrm{~S}$ was $14.5 \times$ $10^{6}$ counts $/ \mathrm{min} / \mu$ mole and that of DL-cysteine- $3-{ }^{14} \mathrm{C}$ was $5.8 \times 10^{6} \mathrm{counts} / \mathrm{min} / \mu$ mole. The results of these incubations are shown in table VI, from which it can be seen that no cystathionine was formed during incubation in the absence of homoserine (tubes 6-2 and 6-4). When both homoserine and labelled cysteine were present, however, cystathionine was synthesized (tubes 6-3 and 6-5). The specific activities of the cystathionine formed from ${ }^{35} \mathrm{~S}$ and ${ }^{14} \mathrm{C}$-cysteine were close to the specific activities of the labelled substrates.

Figures 2, 3, 4 and 5 show the chromatograms of in-

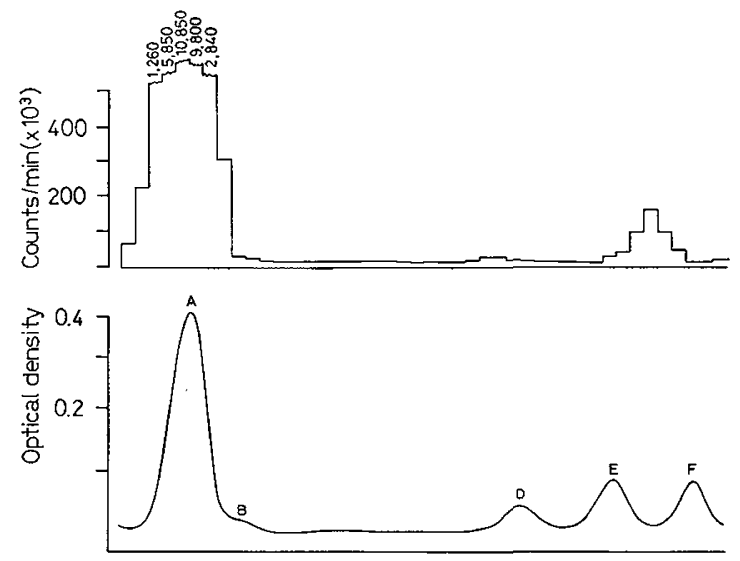

Fig. 2. Part of the column chromatogram and the radioactivity of the corresponding fractions of incubate 6-2. The ninhydrin peaks (lower curve) are: $\mathrm{A}=$ cystine, $\mathrm{B}=$ methionine, $\mathrm{D}=$ isoleucine, $\mathrm{E}=$ leucine and $\mathrm{F}=$ norleucine. The total radioactivity (in counts per minute) of each fraction is shown on the upper tracing.

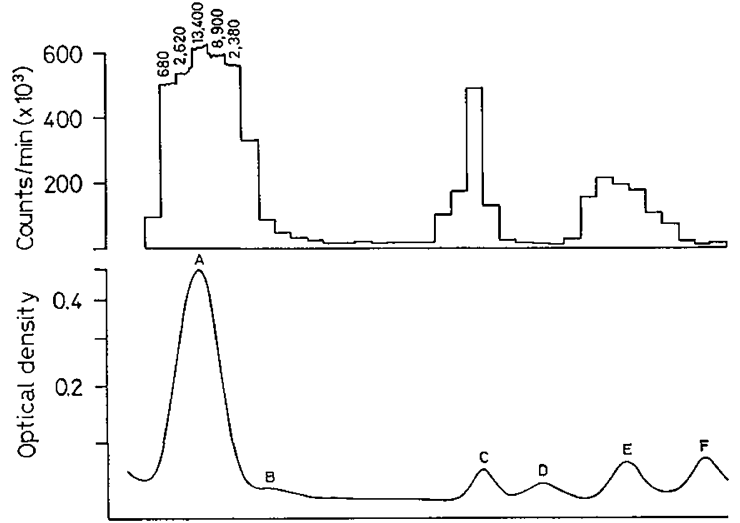

Fig. 3. Part of the column chromatogram and the radioactivity of the corresponding fractions of incubate 6-3. The ninhydrin peaks same as figure $2, \mathrm{C}=$ cystathionine.
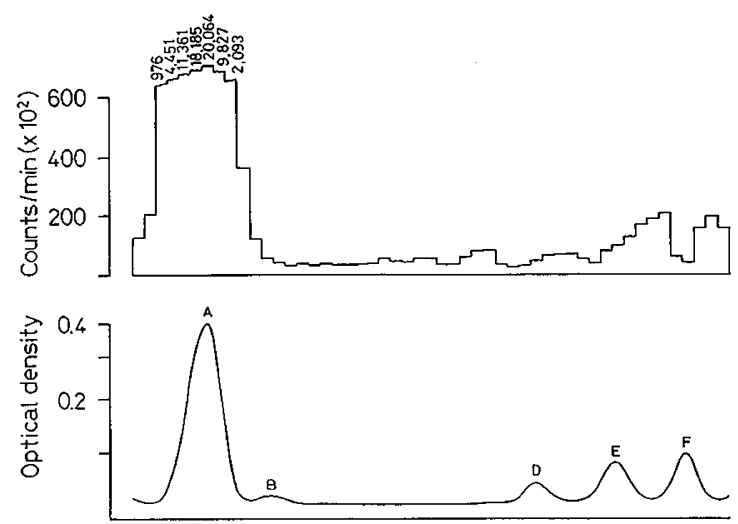

Fig.4. Part of the chromatogram and the radioactivity of the corresponding fractions of incubate $6-4$. The ninhydrin peaks same as in figure 2.

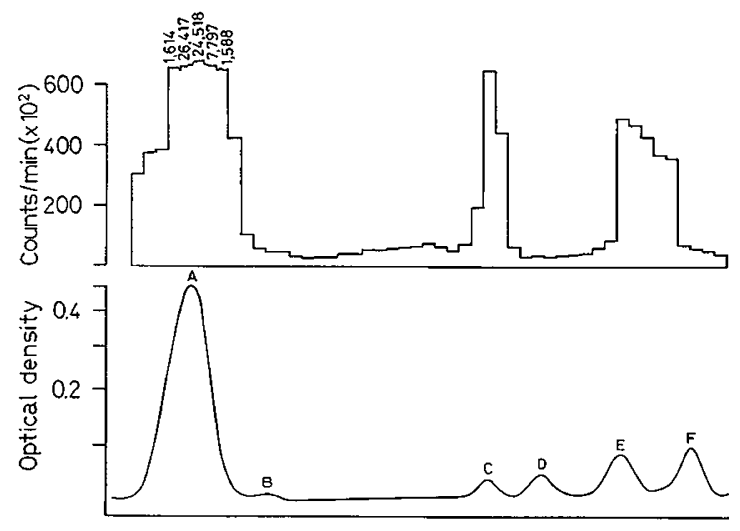

Fig.5. Part of the chromatogram and the radioactivity of the corresponding fractions of incubate 6-5. The ninhydrin peaks same as figure 3 . 


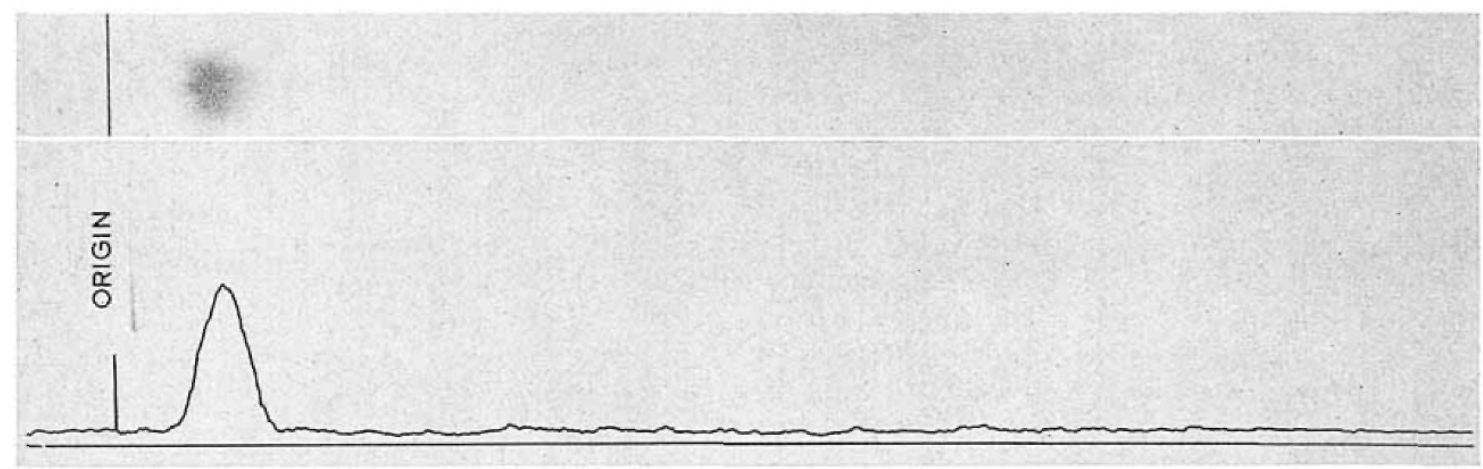

Fig.6. Paper chromatogram of peak $\mathrm{C}$ from tube 6-3 (butanol:acetic acid:water) and radioactivity tracing of the chromatogram.

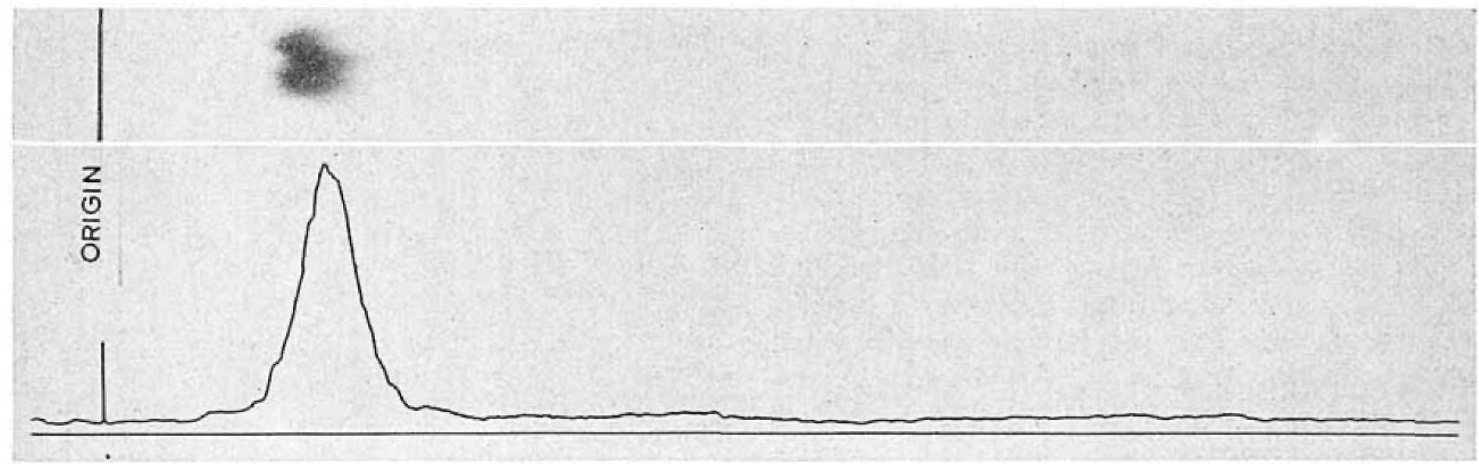

Fig.7. Paper chromatogram of peak $\mathrm{C}$ from tube $6-3$ (methanol: water:pyridine) and radioactivity tracing of the chromatogram.

cubates $6-2,6-3,6-4$ and $6-5$ respectively. It can be seen that the cystathionine peaks obtained in tubes $6-3$ and $6-5$ are coincident with the radioactive peaks. To verify the identity of these peaks, the three fractions containing the highest counts (corresponding to cystathionine) were partitioned by unidimensional paper chromatography with an authentic cystathionine marker. Two different solvent systems were used: butanol: acetic acid: water (120:30:50 by vol) and methanol: water: pyridine (160:40:8 by vol) [25]. The chromatograms were scanned for radioactivity and then stained with $0.1 \%$ ninhydrin in butanol. It can be seen from figures 6 to 9 that on all chromatograms there was only a single major radioactive peak which coincided with a single ninhydrin marker spot. The $\mathrm{R}_{\mathrm{F}}$ of the marker was 10 in butanol:acetic acid: water and 19 in methanol: water:pyridine, and was the same as that reported for cystathionine [25]. It was concluded, therefore, that the radioactive material appearing in the cystathionine position on column chromatography was truly cystathionine.

\section{Loading Experiments}

Two days before the experiment, Case 1 was given $100 \mathrm{mg}$ of pyridoxine intramuscularly. One day before the experiment, column chromatography of plasma and urine showed no ninhydrin peak in the cystathionine position. None had been found on several previous occasions while the patient was on the same standard low methionine diet she received during the experiment. On the morning of the experiment, an intramuscular injection of $100 \mathrm{mg}$ of pyridoxine and an oral load of L-cystine and DL-homoserine $(100 \mathrm{mg}$ of each amino acid per kg of body weight) were given at 9 a.m., and a similar dose of amino acids was given at 12 noon. The standard low methionine diet was given at the usual meal times. Venous blood was obtained at $0,2,4$ and 6 hours after the first loading; urine was collected continuously for 24 hours in 6 -hour periods. The patient had diarrhea for 24 hours after loading. The diarrhea was not infective in origin. Tables VII and VIII show the concentrations of the relevant amino acids in the plasma and urine respectively. It can be seen from 


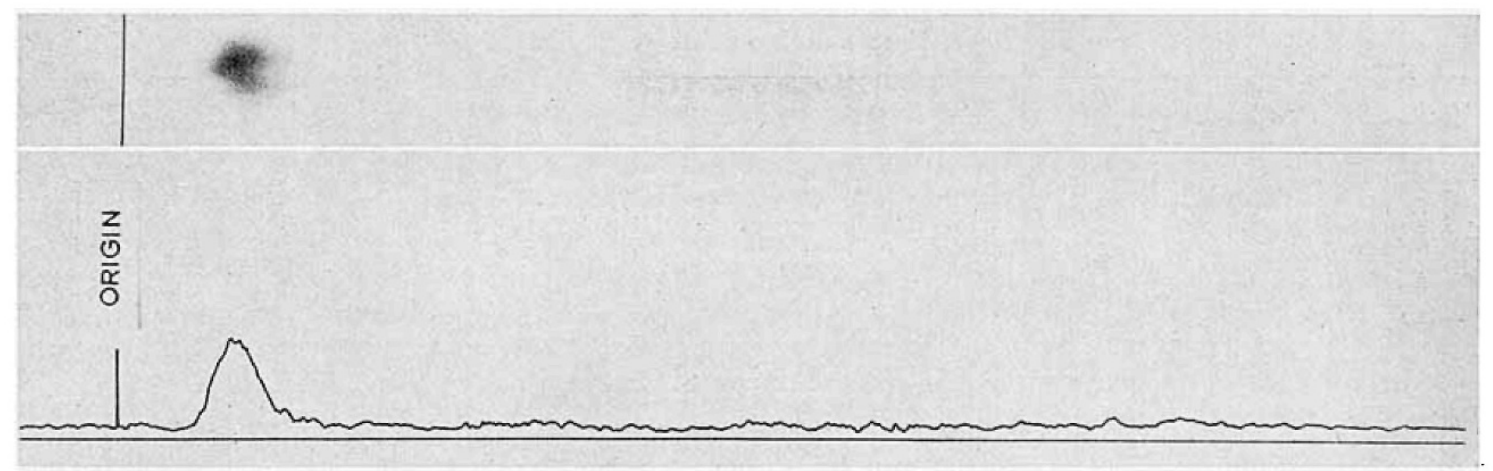

Fig. 8. Paper chromatogram of peak $\mathrm{C}$ from tube 6-5 (butanol:acetic acid:water) and radioactivity tracing of the chromatogram.

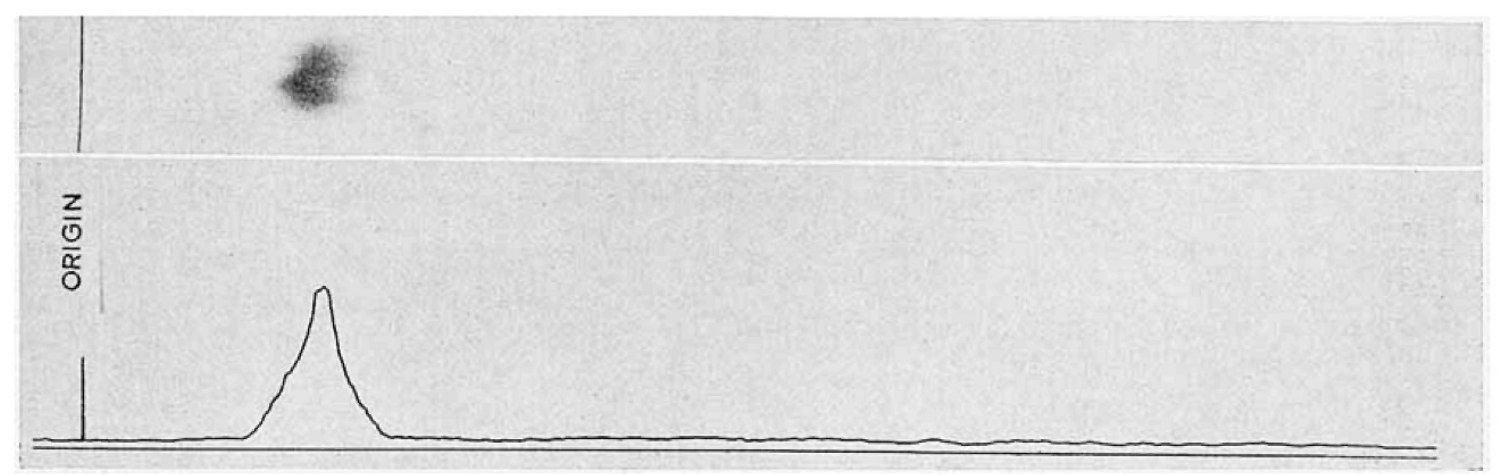

Fig. 9. Paper chromatogram of peak $\mathrm{C}$ from tube 6-5 (methanol: water:pyridine) and radioactivity tracing of the chromatogram.

table VII that before loading, the concentration of cystine in the patient's plasma was less than normal, suggesting that the total amount ingested daily was low. Poor intestinal absorption of cystine from the load is suggested by the complete absence and the low plasma concentration of cystine at 2 and 4 hours respectively, and by the small amount excreted in the urine. While cystathionine was found in the urine after loading, this amino acid could not be detected in the plasma.

Case 2 was given $100 \mathrm{mg}$ of pyridoxine intramuscularly the day before and during the experiment. No cystathionine had been detected in the plasma or urine on many occasions prior to the load. To overcome the diarrhea and the poor intestinal absorption of cystine

encountered in Case 1, L-cysteine hydrochloride was substituted for cystine. (Cysteine was reported to be absorbed much more efficiently than cystine [22].) Seventy $\mathrm{mg} / \mathrm{kg}$ of body weight of cysteine and of homoserine was given to Case 2 at 9 a.m., at 12 noon and at 4. p.m. No diarrhea was observed during the next 24 hours or subsequently. Tables IX and X show the relevant amino acid concentrations in her plasma and urine. From table IX it is clear that cysteine loading resulted in higher concentrations of cystine (cysteine) in the plasma and moderate excretion in the urine. The amount of cystathionine excreted in the urine was higher than that in Case 1. Again, no cystathionine was detectable in the plasma at any time after the loads. 
Table VII. Plasma amino acids $(\mu \mathrm{mole} / \mathrm{ml})$, Case 1

\begin{tabular}{lllll}
\hline Hours after first loading & 0 & 2 & 4 & Normal range \\
\hline Homoserine & N.D. & 0.109 & 0.145 & N.D. \\
Cystine & 0.009 & N.D. & 0.014 & $0.045-0.077$ \\
Methionine & 0.044 & 0.057 & 0.035 & $0.011-0.016$ \\
Cystathionine & N.D. & N.D. & N.D. & N.D. \\
Homocystine & 0.006 & 0.004 & 0.003 & N.D. \\
\hline
\end{tabular}

Blood sample at the 6 th hour after loading was lost due to accidental breakage of container.

1 Not detectable.

Table VIII. Urine amino acids $(\mu$ mole $/ 6 \mathrm{~h})$, Case 1

\begin{tabular}{lllllllll}
\hline $\begin{array}{l}\text { Hours after } \\
\text { first loading }\end{array}$ & -6 to 0 & 0 to 6 & 6 to 12 & 12 to 18 & 18 to 24 & $\begin{array}{l}\text { Total } \\
\text { 24 hours }\end{array}$ & $\begin{array}{l}\text { Normal range } \\
24 \text { hours }\end{array}$ \\
\hline Volume & $115 \mathrm{ml}$ & $137 \mathrm{ml}$ & $98 \mathrm{ml}$ & $60 \mathrm{ml}$ & $215 \mathrm{ml}$ & $625 \mathrm{ml}$ & \\
Homoserine & N.D. & 2 & 2 & 2 & 335.00 & 2 & N.D. \\
Cystine & N.D. & N.D. & 1.70 & 0.90 & 1.90 & 4.50 & $0-137$ \\
Methionine & 2.68 & 11.00 & 5.51 & 9.20 & 7.60 & 33.30 & $20-80$ \\
Cystathionine & N.D. & 1.40 & 1.52 & 0.90 & 0.63 & 4.45 & $4.0^{3}$ \\
Homocystine & 9.80 & 47.80 & 23.00 & 26.00 & 43.30 & 150.30 & N.D. \\
\hline
\end{tabular}

1 Not detectable.

${ }^{2}$ Concentration too high for accurate measurement by Technicon Recorder.

3 From Gerritsen and Waisman [9].

Table IX. Plasma amino acids $(\mu \mathrm{mole} / \mathrm{ml})$, Case 2

\begin{tabular}{lllllll}
\hline $\begin{array}{l}\text { Hours after } \\
\text { first loading }\end{array}$ & 0 & 2 & 5 & 10 & 12 & Normal range \\
\hline Homoserine & N.D.1 & 0.470 & 0.466 & 0.291 & 0.150 & N.D. \\
Cystine & 0.029 & 0.127 & 0.089 & 0.061 & 0.046 & $0.045-0.077$ \\
Methionine & 0.028 & 0.060 & 0.020 & 0.019 & 0.056 & $0.011-0.016$ \\
Cystathionine & N.D. & N.D. & N.D. & N.D. & N.D. & N.D. \\
Homocystine & 0.034 & N.D. & N.D. & N.D. & N.D. & N.D. \\
\hline
\end{tabular}

1 Not detectable.

Table $X$. Urine amino acids ( $\mu$ mole/ $6 \mathrm{~h})$, Case 2

\begin{tabular}{lccllllll}
\hline $\begin{array}{l}\text { Hours after } \\
\text { first loading }\end{array}$ & -6 to 0 & 0 to 6 & 6 to 12 & 12 to 18 & 18 to 24 & $\begin{array}{l}\text { Total } \\
24 \text { hours }\end{array}$ & $\begin{array}{l}\text { Normal range } \\
24 \text { hours }\end{array}$ \\
\hline Volume & $124 \mathrm{ml}$ & $196 \mathrm{ml}$ & $40 \mathrm{ml}$ & $73 \mathrm{ml}$ & $43 \mathrm{ml}$ & $352 \mathrm{ml}$ & \\
Homoserine & N.D. & 2 & 2 & 2 & 2 & 2 & N.D. \\
Gystine & 10.70 & 23.00 & 3.20 & 11.80 & 3.09 & 51.09 & $0-137$ \\
Methionine & 4.18 & 7.76 & 2.12 & 6.25 & 1.60 & 17.73 & $20-80$ \\
Cystathionine & N.D. & 2.82 & 0.73 & 7.85 & trace & 11.40 & $4.0^{3}$ \\
Homocystine & 5.20 & 3.00 & 4.37 & 1.13 & 1.40 & 9.90 & N.D. \\
\hline
\end{tabular}

1 Not detectable.

2 Concentration too high for accurate measurement by Technicon Recorder.

${ }^{3}$ From Gerritsen and Waisman [9]. 


\section{Discussion}

MAtsuo and Greenberg [15] crystallized an enzyme from rat liver that cleaved cystathionine into cysteine and homoserine; the latter is not released into the medium but is deaminated to $\alpha$-oxobutyrate. This crystalline enzyme, cystathionase, also catalyzes the formation of cystathionine from homoserine and cysteine.

It is apparent from table $I$ that in liver homogenates of rats, cystathionine can be synthesized from homocysteine and serine, as well as from homoserine and cysteine, and that the cystathionine is cleaved into cysteine (and presumably $\alpha$-oxobutyrate). Thus the amount of cystathionine found in the incubates is the resultant of at least three reactions, synthetic and degradative, occurring simultaneously.

Homogenates of human liver are also able to synthesize cystathionine from homoserine and cysteine. Although the amount of cystathionine found in these homogenates was small, experiments with ${ }^{14} \mathrm{C}$ and ${ }^{35} \mathrm{~S}$-cysteine show clearly that the label is incorporated into cystathionine.

A similar incorporation of label had been demonstrated in a case of homocystinuria. Cystathionine was found only in the incubates containing both homoserine and cysteine, and the specific activities were close to those of the substrates, suggesting that, in this patient, all of the cystathionine had been synthesized from the exogenous substrates.

The experiments using oral loading with amino acids have shown that cystathionine is excreted in the urine of the homocystinuric patients after administration of homoserine and cystine or preferably, cysteine. Cystathionine could not be detected in the plasma even when $1.5 \mathrm{ml}$ was chromatographed by column chromatography. The urinary excretion rate is similar to that reported in normal individuals without amino acid loading by GERritsen and WAISMAN [9] and by BRENTON et al. [2].

In the treatment of homocystinuria, a low methionine intake with cystine supplement has been tried $[13,19]$, on the assumption that excess methionine or its metabolites and the deficiency of cystine are the damaging factors. The long-term prognosis remains in doubt, however, as several children have been reported to be apparently normal in the first years of life. The importance of cystathionine, especially in the development and function of the brain, is unknown.

Our studies indicate a possible means of providing these patients with cystathionine. Although the amino acid could not be detected in the patient's plasma, it should be remembered that cystathionine is not normally present in plasma in sufficient concentration to be measured by these methods. It must be assumed, therefore, that the brain is able either to concentrate cystathionine transported there from the liver or to synthesize it in situ. It would appear from the observations of Hope [12], Gaitonde and Righter [7] and MuDD et al. [17] that cystathionine is mainly produced in situ in the brain. We do not know if cystathionine can be synthesized from homoserine and cysteine in the brain and, if it is, whether adequate concentration of homoserine and cysteine could be built up locally to make good the deficiency arising from the cystathionine synthetase defect. Ultimately, determination of cystathionine in different tissues, especially the brain, will be the only valid evidence for the biochemical success or failure of the dietary supplement. Meanwhile, the findings presented here would seem to warrant an investigation of the effect of prolonged administration of homoserine. If this can be shown to be harmless, its use, in conjunction with cysteine, may be of value in raising the intracellular concentration of cystathionine and may possibly improve the prognosis of homocystinuria.

\section{Summary}

1. Rat and normal human liver homogenates were demonstrated to catalyzse the formation of cystathionine from homocysteine and serine, as well as from homoserine and cysteine.

2. Formation of labelled cystathionine was demonstrated from DL-cysteine- $3-{ }^{14} \mathrm{C}$ or DL-cysteine-- ${ }^{35} \mathrm{~S}$ and L-homoserine in a liver homogenate from a homocystinuric patient. The specific activities of the cystathionine were close to those of the substrates.

3. Oral loading of cystine or cysteine, together with homoserine in two patients with homocystinuria, resulted in urinary excretion of cystathionine.

4. These findings suggest that supplementation of the homocystinuric patient's diet with homoserine and cysteine may be effective in raising the intracellular concentration of cystathionine and may possibly improve the prognosis of the disease.

\section{References and Notes}

1. Baldwin, E.M.; Clayton, B.E.; Perkins, P.; Mitchell, J. and Renwrak, A. G. G.: Collection of urine and faeces in children, with a note on fat balances. Arch. Dis. Ghildh. 37: 488 (1962).

2. Brenton, D.P.; Gusworth, D.C. and Gaull, G.E.: Homocystinuria: Biochemical studies of tissues including a comparison with cystathioninuria. Pediatrics 35: 50 (1965).

3. Garson, N.A.J.; Gusworth, D. C.; Dent, C.E.; Field, G. M. B.; NeILl, D.W. and Westall, R. G.: 
Homocystinuria: A new inborn error of metabolism associated with mental deficiency. Arch. Dis. Ghildh. 38: 425 (1963).

4. Field, G.M.B.; Carson, N.A.J.; Cusworth, D. C. ; Dent, C. E. and NeIrL, D.W.: Homocystinuria. A new disorder of metabolism. Abstr. Xth Internat. Congr. Pediat., Lisbon, 1962, p. 274.

5. Finkelstein, J.D.; Mudd, S.H.; Irreverre, F. and LASTER, L. : Homocystinuria due to cystathionine synthetase deficiency: the mode of inheritence. Science 146: 785 (1964).

6. Frimpter, G.W. and Greenberg, A.J.: Renal clearance of cystathionine in homozygous and heterozygous cystathioninuria, cystinuria and the normal state. J. clin. Invest. 46: 975 (1967).

7. Gaitonde, M.K. and Richter, D.: The metabolism of ${ }^{35} \mathrm{~S}$-methionine in the brain; in The metabolism of the nervous system (ed. Richter, D., p. 449 Pergamon Press, London 1957).

8. Gerritsen, T.; Vaughn, J.G. and Waisman, H. A.: The identification of homocystine in the urine. Biochem. biophys. Res. Commun. 9: 493 (1962).

9. Gerritsen, T. and Waisman, H. : Homocystinuria : an error in the metabolism of methionine. Pediatrics 33: 413, (1964).

10. Grbson, J.B.; Garson, N.A.J. and Neill, D.W.: Pathological findings in homocystinuria. J.clin. Path. 17: 427 (1964).

11. GiLl, D. M. : Use of glass fibre paper in liquid scintillation counting. Nature (Lond.) 202: 626 (1964).

12. Hope, D.B.: Studies of taurine and cystathionine in brain. Proceedings of Fourth International Congress of Biochemistry, Vienna, 1958, vol. XIII, p. 63 (Pergamon Press, London 1958).

13. Komrower, G.M.; Lambert, A. M.; Gusworth, D.C. and Westall, R.G.: Dietary treatment of homocystinuria. Arch. Dis. Childh. 41: 666 (1966).

14. Laster, L.; Spaeth, G.L.; Mudd, S.H. and Finkelstern, J.D.: Homocystinuria due to cystathionine synthetase deficiency. Ann. intern. Med. 63: 1117 (1965).

15. Matsuo, Y. and GreenberG, D. M.: A crystalline enzyme that cleaves homoserine and cystathionine. J. biol. Chem. 234: 516 (1959).

16. Mudd, S.H.; Finkelstein, J.D.; Irreverre, F. and LASTER, L.: HOMOCYSTINURIA: an enzymatic defect. Science 143: 1443 (1964).

17. Mudd, S.H.; Finkelstein, J.D.; Irreverre, F. and LAster, L.: Transsulfuration in mammals. J.biol. Chem. 240: 4382 (1965).
18. O'Brien, D. and Ibbott, F. A. (eds.) : Laboratory manual of pediatric micro- and ultramicro-biochemical techniques, 3rd ed., p. 260 (Harper and Row, New York 1962).

19. Perry, T.L.; Dunn, H. G.; Hansen, S. and MacDougall, P.D.: Early diagnosis and treatment of homocystinuria. Pediatrics 37: 502 (1966).

20. Perry, T.L.; Hansen, S.; MagDougall, L. and WARRINGTON, P.D.: Sulfur-containing amino acids in the plasma and urine of homocystinuric. Clin. Chim. Acta 15: 409 (1967).

21. PIEz, K. A. and Morris, L. : A modified procedure for automatic analysis of amino acids. Anal.Biochem. 1: 187 (1960).

22. Rosenberg, L.E.; Grawhall, J. C. and Segal, S.: Intestinal transport of cystine and cysteine in man; evidence for separate mechanisms. J.clin. Invest. 46: 30 (1967).

23. Schimke, R. N.; MaKusick, V.A.; Huang, T. and Pollack, A. D. : Homocystinuria: Studies of $20 \mathrm{fa}-$ milies with 38 affected members. J.amer.med. Ass. 193: 711 (1965).

24. Shrmizu, H.; Kakimoto, Y. and Sano, I.: A method of determination of cystathionine and its distribution in human brain. J. Neurochem. 13: 65 (1966).

25. Smiтh, I.: Chromatographic and electrophoretic techniques, p.93 (Interscience, 1963).

26. Tallan, H.H.; Moore, S. and Stein, W.H.: Lcystathionine in human brain. J. biol. Chem. 230: 707 (1958).

27. The authors wish to thank Dr. M. Ellrs and Mr. K. Dixon for their valuable suggestions, Miss A.M. LAMBERT for technical assistance, Mr. A.R. AnsCOMBE and Mr. B. Torrance for the liver biopsies, and Mr. E. Sмгтн, medical artist and the Department of Medical Illustration.

28. This investigation was supported by the Rag Fund of the University of Manchester, the Manchester Regional Hospital Board, the Friends of the Royal Manchester Children's Hospital and the Wellcome Trust. P.W.K.W. was supported by a grant from the Children's Research Fund.

29. Report of the Commission on Enzymes of the International Union of Biochemistry (Pergamon Press, New York 1961).

30. Requests for reprints should be addressed to: PAUL W.K.Wong, M.D, Mount Sinai Hospital Medical Center, California Avenue at 15th Street, Chicago, I11. 60608 (USA). 